\title{
TOWARDS A MULTI-LEVEL APPROACH TO THE EMERGENCE OF MEANING PROCESSES IN LIVING SYSTEMS
}

\author{
João Queiroz ${ }^{1,2,3,4}$ and Charbel Niño El-Hani ${ }^{2,3,4}$ \\ ${ }^{1}$ Dept. Computer Engineering and Industrial Automation, FEEC - UNICAMP. \\ ${ }^{2}$ Research Group on History, Philosophy, and Biology Teaching, Institute of Biology, \\ (UFBA). \\ ${ }^{3}$ Graduate Studies Program in History, Philosophy, and Science Teaching (UFBA/ \\ UEFS). \\ ${ }^{4}$ Graduate Studies Program in Ecology and Biomonitoring (UFBA).
}

Mailing Address: Department of General Biology, Institute of Biology, Federal University of Bahia, Campus de Ondina, Ondina, Salvador-BA, Brazil. CEP: 41270-190. E-mails: queirozj@dca.fee.unicamp.br; charbel@ufba.br

Received 5 January 2006; accepted in revised form 11 April 2006

\begin{abstract}
Any description of the emergence and evolution of different types of meaning processes (semiosis, sensu C.S.Peirce) in living systems must be supported by a theoretical framework which makes it possible to understand the nature and dynamics of such processes. Here we propose that the emergence of semiosis of different kinds can be understood as resulting from fundamental interactions in a triadically-organized hierarchical process. To grasp these interactions, we develop a model grounded on Stanley Salthe's hierarchical structuralism. This model can be applied to establish, in a general sense, a set of theoretical constraints for explaining the instantiation of different kinds of meaning processes (iconic, indexical, symbolic) in semiotic systems. We use it to model a semiotic process in the immune system, namely, B-cell activation, in order to offer insights into the heuristic role it can play in the development of explanations for specific semiotic processes.
\end{abstract}

Key Words: meaning processes, semiosis, emergence, types of signs, levels

\section{INTRODUCTION}

The emergence and evolution of new kinds of information interpretation systems in living beings (conceived here as semiotic systems) have received a great deal of attention recently (Jablonka, 1994; Jablonka and Szathmáry, 1995; Maynard Smith and Szathmáry, 1995, 1999; Jablonka et al., 1998). It is even the case that the evolution of different ways of storing, transmitting, and interpreting information' can be treated as a major theme in the history of life (Jablonka, 2002). Despite the growing number of works on the emergence of meaning processes in biological systems (e.g., Roederer, 2005; Adami, 2004; Nöth, 1994, 2004; Gregersen, 2003; Maynard Smith, 2000; Oyama, 2000; Banathy, 1998; Cariani, 1998; Hoffmeyer, 
1996; Emmeche and Hoffmeyer, 1991), it is still the case that a careful analysis of central concepts in such an endeavor, such as 'meaning' and 'emergence', has to be developed.

Any description of the emergence of different types of meaning processes in biological systems must be supported by a theoretical framework which makes it possible to understand the nature and dynamics of such processes. We argue in this paper that a proper basis for developing such a framework is found in C. S. Peirce's theory of signs. From the perspective of this theory, meaning processes are defined as semiosis, a triadic irreducible and processual relationship between signs, objects, and interpretants (see below). Thus, the problem of the emergence of meaning processes in biological systems can be treated in parallel with the problem of the emergence of semiosis in semiotic systems. Furthermore, a theoretical framework capable of addressing these processes in living beings should describe a transition from reactive to semiotic systems, ${ }^{1}$ and from iconic and indexical to symbolic systems. In this paper, we are particularly interested in discussing some theoretical requisites for building such a framework which follows from a Peircean account of meaning processes. We are guided by a long-standing idea, found in works, for instance, by Pietarinen (2005), Freadman (2004), Hookway (2002),

\footnotetext{
${ }^{1}$ According to Nolfi (2002), reactive systems "are systems in which sensors and motors are directly linked and which always react to the same sensory state with the same motor action. In these systems internal states, if any, play a comparatively limited role in determining the motor output of the system." By contrast, we can say that in semiotic systems internal states are crucial for the interpretation of outer states perceived through sensory apparatuses, and, as sign interpretation plays a fundamental role in the processes through which the system answers to environmental cues, different actions can result from the same sensory stimulus, depending on the relationships established within the system and between the system and its environment. Thus, the responses of semiotic systems to sensory stimuli are contingent, and, as Peter Cariani (personal communication) reminded us, the internal memory of the system and the degree of separation of sensory inputs and motor/behavioral outputs via successive layers of representation have to be taken in due account. The contingency of the system's responses upon its internal states is a fundamental feature of learning processes through which subsequent inputs are contextualized and some responses become more likely than others in the semiotic system. The distinction between reactive and semiotic systems can be extended to account for a distinction within a living system (notwithstanding its general semiotic nature) between reactive and semiotic processes. In our view, it is not the case that the qualification 'semiotic' should be added in an indiscriminate manner to all functional processes in organisms. It is not the case, for instance, that every enzymatic reaction in a biosynthetic pathway will be a semiotic process, even though that reaction can answer to regulation via signaling pathways. The enzymatic reaction can be simply a reactive process, in which, once an input is present (say, in the form of a substrate plus a regulatory molecule), the same product (output) will always follow. In this case, the regulation of the reaction will be semiotic (given the involvement of a signaling process), but the reaction in itself will not turn out to be equally semiotic for being regulated in such a manner. In our understanding, this would be an overextension of a characteristic of the signaling pathway to the event or pathway regulated by it.
} 
Bergman (2000a,b), Deacon (1997), Fetzer (1997, 1988), Houser et al. (1997); Noble and Davidson (1996), Emmeche (1991), and Ransdell (1977), that the semiotics of C. S. Peirce offers powerful tools for the investigation of meaning, language and communication.

We assume, first, that semiosis can be fruitfully treated as an emergent process. We follow Rescher in his definition of a "process" as ". . . a coordinated group of changes in the complexion of reality, an organized family of occurrences that are systematically linked to one another either causally or functionally" (Rescher, 1996, p. 38). Rosenthal (1994, p. 27) argues that "meanings" should be understood as relational structures that emerge from behavioral patterns. A precise interpretation of this statement - with which we basically agree - demands a clear understanding about the characterization of structures as emergent systemic properties. Furthermore, it also depends on a good grasp of the relationship between emergent properties and processes, observed at a higher level in a system, and patterns of behavior observed at lower levels. In an effort to expand on Rosenthal's idea, it is very important to employ the concept of emergence in its technical, rather than in an ordinary, colloquial sense. It is a relevant problem how to properly connect discussions about emergence and meaning processes. A systematic approach to this topic seems to be particularly crucial in the domain of debates concerning the emergence of meaning in biological and artificial systems, particularly because there is a tendency to use the concept of emergence in a rather informal sense, without clearly explaining what it means (for critical commentaries, see Cariani, 1989; Bedau, 2002; El-Hani, 2002).

We propose in this paper that the emergence of semiosis in semiotic systems can be understood as resulting from fundamental interactions in a triadically-organized hierarchical process. Following Salthe's (1985) basic triadic system, we describe those interactions in terms of the following model: (i) semiosis is described as a process at a focal level, where we actually observe a given kind of meaning process we intend to explain; (ii) a lower, micro-semiotic level, is described as establishing the potentialities or initiating conditions for semiosis as an emergent process at the focal level; and, finally, (iii) we consider a higher, macro-semiotic level, which establishes boundary conditions which coordinate or regulate the dynamics at the focal level. Initiating and boundary conditions are interpreted in this model as constraints. It is important also to emphasize that this is a synchronic picture of the process rather than a diachronic, developmental one.

We will begin by presenting some basic notions in Peircean semiotics, including Peirce's 'most fundamental division of signs'. Subsequently, we will move to a discussion about the technical meaning of 'emergence' and the application of emergentist thought to an understanding of semiosis. Finally, we will discuss in detail the model for the emergence of meaning processes (semiosis) sketched above and apply it to analyze a specific semiotic process in a living system.

\section{SOME BASIC NOTIONS IN C. S. PEIRCE'S SEMIOTICS}

According to Peirce, any description of semiosis, i.e., the action of a sign, should necessarily treat it as a relation constituted by three irreducibly connected terms 


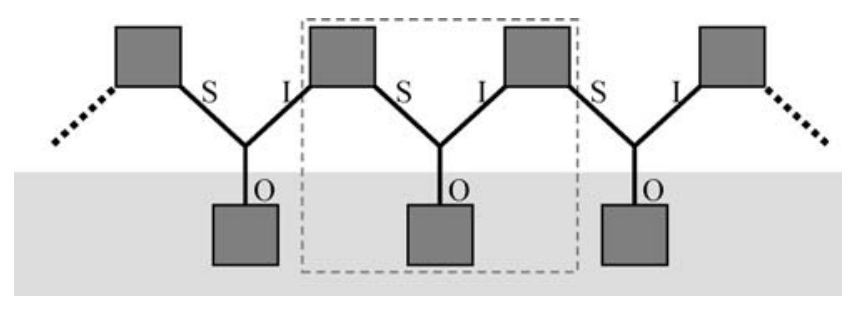

Figure 1. The triadic relation S-O-I forming a chain of triads. The grey area at the bottom of the figure shows that all signs in the chain of triads refer to the same object.

(sign-object-interpretant, S-O-I) (Figure 1), which are its minimal constitutive elements (CP 5.484, EP 2:171). ${ }^{2}$

"A sign is anything which determines something else (its interpretant) to refer to an object to which [it] itself refers (its object) in the same way, the interpretant becoming in turn a sign, and so on ad infinitum" (CP 2.303).

Semiosis entails the instantiation of chains of triads. As Savan (1986, p. 134) argues, an interpretant is both the third term of a given triadic relation and the first term (sign) of a subsequent triadic relation. This is the reason why semiosis cannot be defined as an isolated triad; it necessarily involves chains of triads (Figure 1).

Peirce also defines a sign as a medium for the communication of a form or habit embodied in the object to the interpretant (De Tienne, 2003; Hulswit, 2001; Bergman, 2000a), so as to constrain (in general) the interpretant as a sign or (in biological systems) the interpreter's behavior (Figure 2):

“... a Sign may be defined as a Medium for the communication of a Form. [...]. As a medium, the Sign is essentially in a triadic relation, to its Object which determines it, and to its Interpretant which it determines. [...]. That which is communicated from the Object through the Sign to the Interpretant is a Form; that is to say, it is nothing like an existent, but is a power, is the fact that something would happen under certain conditions" (MS 793:1-3. See EP 2.544, n.22, for a slightly different version).

But, how should we understand the term "form" in this context? Peirce stresses that it is nothing like a "thing" (De Tienne, 2003), but something that is embodied in the object as a habit, a "rule of action" (CP 5.397), a "disposition" (CP 2.170), a "real potential" (EP 2.388), or a "permanence ofsome relation" (CP 1.415). It is particularly important

\footnotetext{
${ }^{2}$ We shall follow the practice of citing from the Collected Papers of Charles Sanders Peirce (Peirce, 1931-1935, 1958) by volume number and paragraph number, preceded by 'CP'; the Essential Peirce by volume number and page number, preceded by 'EP'. References to the Annotated Catalogue of the Papers of Charles S. Peirce (1967) will be indicated by 'MS', followed by the manuscript number and pages.
} 


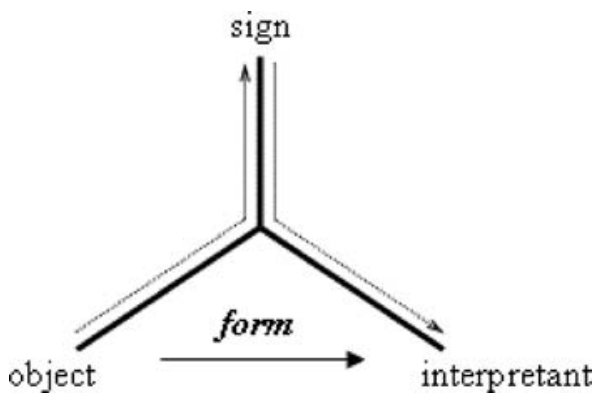

Figure 2. Semiosis as the communication of a form from the object to the interpretant through the sign.

to notice that the form communicated from the object to the interpretant through the sign is not the particular shape of an object, or something alike, but a regularity, a habit which allows a given semiotic system to interpret that form as indicative of a particular class of entities, processes, phenomena, and, thus, to answer to it in a similarly regular, lawful way. Otherwise, the semiotic system would not be really capable of interpretation. It is possible to understand the idea of "interpretation" as basically meaning to subsume a given particular event on a general class of events, and, by thus subsuming it, to answer in a regular way, learnt by living systems through evolution and development (i.e., by evolutionary and somatic learning).

The communication of a form from the object to the interpretant constrains the behavior of an interpreter in the sense that it brings about a constrained set of effects of the object on the interpreter through the mediation of the sign. In short, the meaning of a sign is, for Peirce, an effect of the sign, as a medium for the communication of forms, on an interpreter by means of the triadic relation S-O-I. A meaning process can be thus defined as the action of a sign (semiosis).

\section{SEMIOTIC SYSTEMS AND THE MOST FUNDAMENTAL DIVISION OF SIGNS}

Systems that produce, communicate, receive, compute, and interpret signs of different kinds can be classified as semiotic systems. As Fetzer writes: "What makes a system 'semiotic' thus becomes that the behavior of the system is causally affected by the presence of a sign because that sign stands for something else iconically, indexically, or symbolically, for that system" (Fetzer, 1997, p. 358). By interpreting signs, semiotic systems can show self-corrective behavior (Ransdell, 1977, p. 162). Semiosis can be defined as a self-corrective process involving cooperative interaction between its three components. Such a self-corrective behavior depends on the capability of semiotic systems of using signs as media for the communication of forms from objects to interpretants so as to constrain their own behavior.

Peirce suggested that semiotic systems could be treated as the embodiment of semiotic processes (CP 5.314). Surely, this blurs a distinction between entities and processes which characterized Western thinking for most of its history. Peirce was, however, a process thinker, i.e., a representative of a philosophical tendency of treating processes as being more fundamental than entities as ontological categories (Rescher, 1996). A process 
philosophy can address entities, as Peirce does, as relatively stable bunches of processes. A semiotic system can be understood in these terms as a relatively stable (both spatially and temporally) cluster of semiotic processes.

If we wish to understand how semiotic systems instantiate sign processes, we have to refine our understanding of the types of signs involved in particular semiotic processes. Particularly, we should explore in a more technical way the fundamental differences between iconic, indexical, and symbolic processes, and the Peircean framework is a proper place to pursue such an understanding (Fetzer, 1997, 1988).

In his "most fundamental division of signs" (CP 2.275), Peirce characterized icons, indexes, and symbols as matching, respectively, relations of similarity, contiguity, and law between $\mathrm{S}$ and $\mathrm{O}$ (sign-object relation) in the triad S-O-I.

\subsection{Icons}

Icons are signs which stand for their objects through similarity or resemblance $(\mathrm{CP}$ 2.276 ), irrespective of any spatio-temporal physical correlation that $S$ may have with an existent $\mathrm{O}$ (CP 2.299). If a determinative relation of the sign (S) by the object $(\mathrm{O})$ is a relation of analogy, that is, if $\mathrm{S}$ is a sign of $\mathrm{O}$ in virtue of a certain quality that $\mathrm{S}$ and $\mathrm{O}$ share, then $\mathrm{S}$ is an icon of $\mathrm{O}$. If $\mathrm{S}$ is an icon, then $\mathrm{S}$ communicates to I a quality of $\mathrm{O}$ :

"An Icon is a sign which refers to the Object that it denotes merely by virtue of

characters of its own, and which it possesses, just the same, whether any such

Object actually exists or not" (CP 2.247).

Among the examples of icons mentioned by Peirce, we find images, diagrams, metaphors, pictures, maps, ideographs, hieroglyphs. In terms of cognitive processes, icons are associated with sensory tasks. They are present in the sensorial recognition of external stimuli of any modality, and in the cognitive relation of analogy. According to Sebeok (1989, p. 121), "iconic signs are found throughout the phylogenetic series, in all modalities as circumscribed by the sense organs by which members of a given species are able to inform themselves about their environment. Signal forgery, viz., the phenomenon of mimicry, in fact, all deceptive maneuvering by plants and animals, as well as humans, often crucially depends on iconicity". Figure 3 shows an example of an iconic sign, a structure in a thorn bug which mimics a real thorn.

Figure 4 shows a semiotic interpretation of this case of mimicry. The interpretant is the effect of the thorn on a potential predator of the bug, namely, that the latter will not try to eat the bug. In this iconic sign process, the form which is communicated from the object to the interpretant through the sign is a general similarity between the thorn in the bug and the thorn in the plant. Generally speaking, an iconic sign communicates a habit embodied in an object to the interpretant, so as to constrain the interpreter's behavior, as a result of a certain quality that the sign and the object share.

\subsection{Indexes}

In contrast, if $\mathrm{S}$ is a sign of $\mathrm{O}$ by reason of "a direct physical connection" between them (CP 1.372), then $\mathrm{S}$ is said to be an index of $\mathrm{O}$. In that case, $\mathrm{S}$ is really determined by $\mathrm{O}$, and both must exist as events: "An Index is a sign which refers to the Object that it denotes by virtue of being really affected by that Object" (CP 2.248). The notion of 


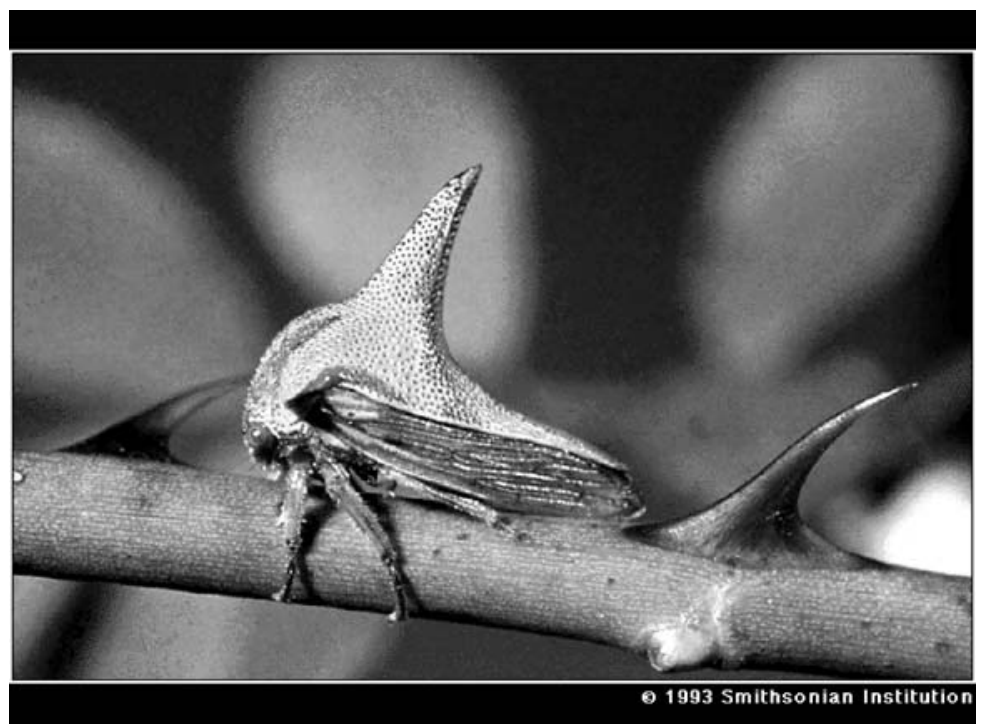

Figure 3. Mimicry offers an example of iconicity. In the picture, a thorn bug (Membracid). (Photo from Chip Clark, Smithsonian Institution, Copyright 1993. Reproduced under permission).

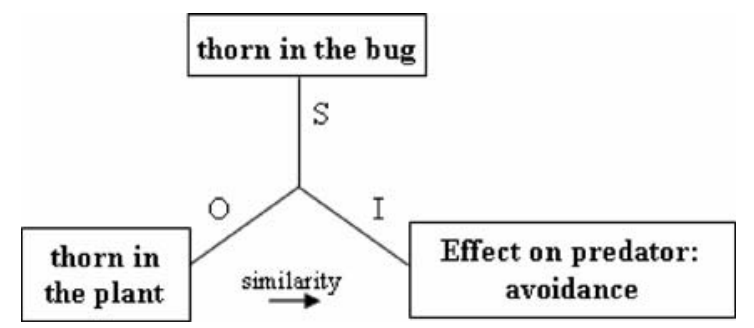

Figure 4. A semiotic interpretation of mimicry in the thorn bug.

spatio-temporal co-variation is the most characteristic property of indexical processes. The examples range from a pronoun demonstrative or relative, which "forces the attention to the particular object intended without describing it" (CP 1.369), to physical symptoms of diseases, photographs, weathercocks, thermometers.

In a Peircean analysis, small red spots in a child's skin, for instance, can be treated as a sign (S) which stands for a disease, say, measles, its object $(\mathrm{O})$, so as to constrain its interpretant, the effect the red spots have on an interpreter, say, a doctor performing a diagnosis. The sign processes involved are indexical. The small red spots operate as signs because they are physically correlated with the disease, which is the primary constraining factor in the process, the form of which will end up producing an effect on the interpreter (Figure 5).

In this indexical sign process, the form which is communicated from the object to the interpretant through the sign is a general physical correlation between measles and 


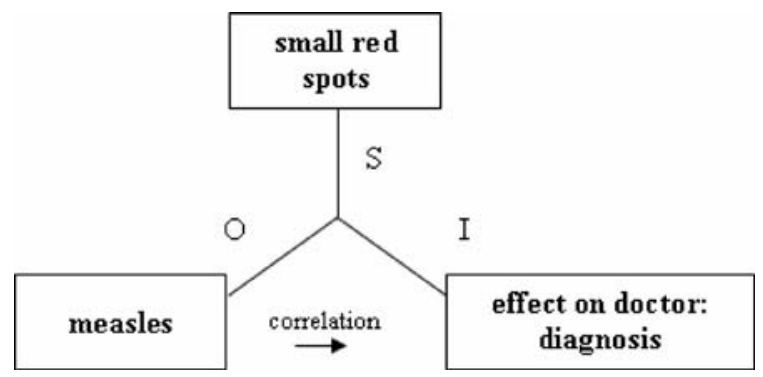

Figure 5. A semiotic interpretation of the diagnosis of measles.

the small red spots in the skin. Generally speaking, an indexical sign communicates a habit embodied in an object to the interpretant as a result of a direct physical connection between sign and object.

\subsection{Symbols}

Finally, in a symbolic relation, the interpretant stands for 'the object through the sign' by a determinative relation of law, rule or convention (CP 2.276). According to Peirce (CP 2.307), a symbol is "a Sign (q.v.) which is constituted a sign merely or mainly by the fact that it is used and understood as such, whether the habit is natural or conventional, and without regard to the motives which originally governed its selection."

We have claimed elsewhere that the alarm-call system used by African vervet monkeys (Cercopithecus aethiops), a well-known case of vocal communication in non-human primates, logically satisfies the Peircean definition of symbol (Queiroz, 2004; Queiroz and Ribeiro, 2002). These primates possess a sophisticated repertoire of vocal signs used for intra-specific alarm purposes regarding imminent predation on the group (Seyfarth et al., 1980). Field studies have revealed three main kinds of alarm-calls, used to warn about the presence of (a) terrestrial stalking predators such as leopards, (b) aerial raptors such as eagles, and (c) ground predators such as snakes (Figure 6). Adult vervets produce these calls only in reference to the presence of specific predators. Such calls motivate whole-group escape reactions that are specific to predator type. For instance, when a 'terrestrial predator' call is uttered, vervets escape to the top of nearby trees; 'aerial predator' calls cause vervets to hide under trees; and 'ground predator' calls elicit rearing on the hind paws and careful scrutiny of the surrounding terrain. These are the interpretants of the calls, as signs.

While adults share a code for predator reference, infant vervet monkeys babble these calls in response to a variety of animals (predators and non-predators), as well as to inanimate objects. Thus, adults pay little attention to infant calls (Cheney and Seyfarth, 1990). The progressive specificity of alarm-call production as vervets grow older indicates that they should learn how to use the calls in the proper context. Field experiments in which predator-specific alarm-calls were played from loudspeakers to groups of wild vervet monkeys showed that adult individuals first responded to playbacks of alarm-calls by looking around in search of a referent (predator). Remarkably, even though this referent was always absent, adult animals consistently fled away to nearby refuges according 

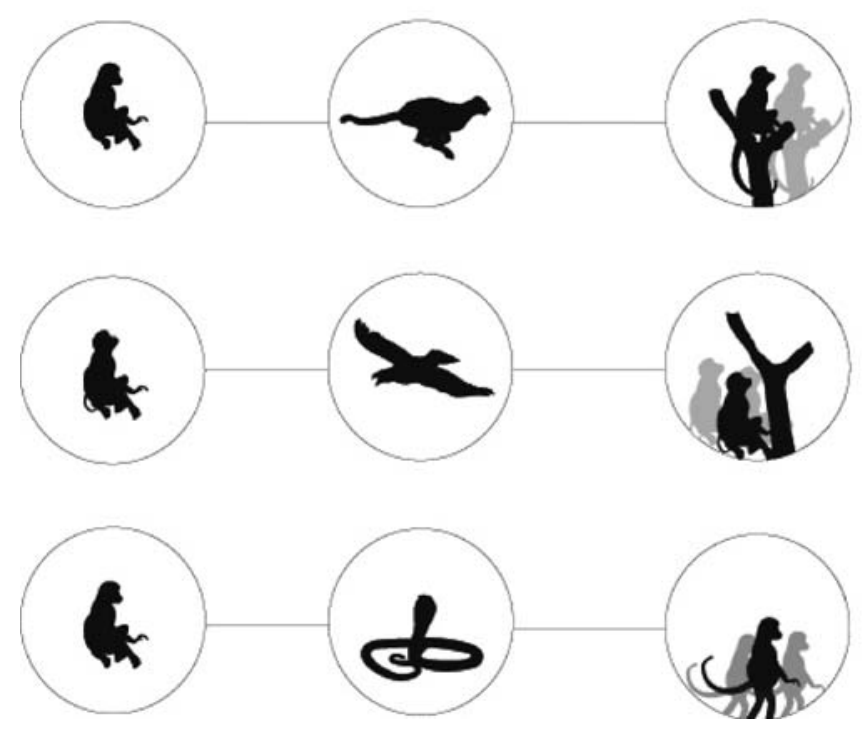

Figure 6. Vervet monkeys' alarm-calls, their referents, and their effects on the monkeys as interpreters (interpretants).

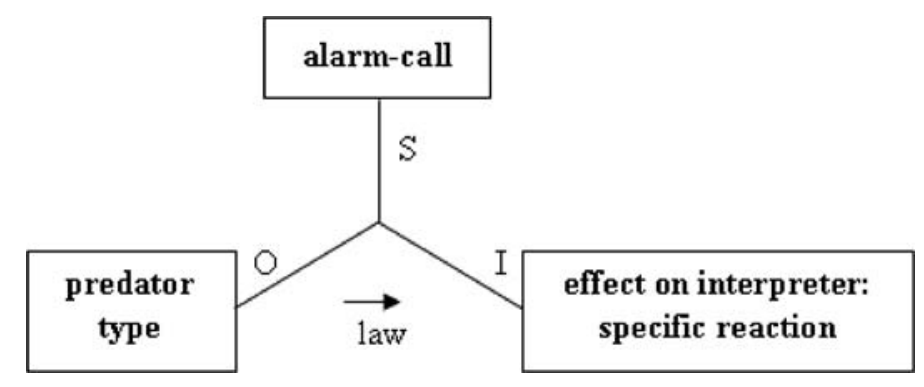

Figure 7. A semiotic interpretation of communication in vervet monkeys.

to the specific type of alarm-call played. Infant monkeys, in turn, responded poorly to playbacks, and teenagers displayed intermediate behaviors.

According to the Peircean classification of signs, if the alarm-call operates in a specific way even in the absence of the external referent, it must be interpreted as a symbol of a predator class. The transition from a sensory scan behavior after the alarm auditory perception to an escape reaction motivated solely by the alarm-call corresponds to the transition from indexical semiosis (interpretation by spatio-temporal coincidence) to symbolic semiosis (interpretation mediated by law or convention) (Figure 7). The object of the sign, in the latter case, is not an object-token but rather a class of objects, i.e., an object-type, and therefore does not need to exist as a singular event. To say that 
an alarm-call is a symbol of a type of predator is equivalent to say that this call evokes a brain representation (of any modality) that stands for the class of predators represented in a law-like and specific way.

In this symbolic sign process, the form which is communicated from the object to the interpretant through the sign is a lawful relationship between a given kind of alarm-call and a given type of predator. Generally speaking, a symbolic sign communicates a habit embodied in an object to the interpretant as a result of a regularity in the relationship between sign and object.

To advance in the discussion of the emergence of semiosis of different kinds, some theoretical constraints should be now put in place. In the following sections, we intend to advance in establishing some of these constraints through a systematic treatment of the concept of emergence in the context of semiotics and the development of the model for explaining the emergence of semiosis briefly described in the introduction.

\section{EMERGENCE AND SEMIOSIS}

Queiroz and El-Hani (2006) stress the importance of ascribing a precise meaning to the concept of emergence and its derivatives whenever they are applied to any domain of phenomena or theories. For instance, in the context of the sciences of complexity, the concept of "emergence" has become very popular, and the very term "emergence" (and its derivatives) has been widely used in research fields such as artificial life and cognitive robotics. But, even though these fields are often described as dealing with emergent computation, little discussion is found in them regarding the precise meaning of the terms "emergence", "emergent", etc. (for critical commentaries, see Cariani, 1989, 1991; Emmeche, 1994, 1997; Ronald et al., 1999; Bedau, 2002; El-Hani, 2002). Given the debates and even confusions that have characterized the understanding of emergence throughout the 20th century (Blitz, 1992; Stephan, 1999), it is crucial to keep it clear what this concept precisely means.

In a technical sense, "emergent properties" constitute a certain class of higher-level properties related in a certain way to the microstructure of a class of systems (adapted from Stephan, 1998, p. 639). The reason why such a broad definition, with open clauses, seems at first more adequate than a definition with more content and precision has to do with the fact that the concept of emergence and its derivatives are employed in the most diverse fields, and, consequently, a more detailed definition is likely to apply to some fields but not to others.

It is true, however, that a more concrete and operational definition is needed when one is dealing with particular cases of emergence. Our claim here is not that one should rest content with the above definition, with such open clauses, but, rather, that attempts to made it more precise should be dealt with case by case, considering specific theoretical and empirical constraints on the meaning of 'emergence' in different research fields. It is part of the task of an emergence theory - applied to a particular research field to fill in the open clauses in this definition (shown in italics). An emergence theory should, among other things, provide an account of which properties (of a given class of systems) should be regarded as emergent, and offer an explanation of the relationship between these properties and the microstructure of the systems. Therefore, when we intend to build an emergentist account of semiotic processes, it is necessary to develop further the main ideas involved in treating those processes as 'emergent'. With this 
purpose, Queiroz and El-Hani (2006) used a set of central characteristics identified by Stephan $(1998,1999)$ in the diversity of emergence theories to pose some fundamental questions that have to be answered in order to ascribe a precise meaning to the term "emergence" in the context of semiotics. They also advanced some tentative answers to them.

First, emergentists should, in a scientific spirit, be committed to naturalism, assuming that only natural factors play a causal role in the universe. Even though naturalism and physicalism philosophically do not coincide, ${ }^{3}$ in the current scientific picture a naturalistically-minded emergentist typically sticks to the idea that all entities consist of physical parts, even though they may be organized in a complex manner and demand higher-level descriptions and explanations. This thesis can be labeled physical monism: there are, and will always be, only physically constituted entities in the universe, and any emergent property or process is instantiated by systems that are exclusively physically constituted.

Accordingly, to build a scientifically-compatible emergentist and semiotic account of sign processes, we should discuss whether semiotic systems and processes are physically constituted. Semiotic processes can only be realized through physical implementation or instantiation (see Ransdell, 1977), and, thus, semiotic systems should be physically embodied. To put it differently, sign processes are relationally extended within the spatiotemporal dimension, so that something physical has to instantiate or realize them (Deacon, 1999; Emmeche, 2003). In this connection, it is important to remember that Peirce considered the material qualities of the sign as the characters that belonged to the sign in itself: "Since a sign is not identical with the thing signified, but differs from the latter in some respects, it must plainly have some characters which belong to it in itself, and have nothing to do with its representative function. These I call the material qualities of the sign" (CP 5. 287).

Emergentist thinking is also characterized by a fundamental commitment to the notion of novelty, i.e., the idea that new systems, structures, entities, properties, processes, and dispositions arise (emerge) in the course of evolution. We should ask, then, whether semiotic systems constitute a new class of systems, instantiating new structures, processes, properties, etc.

We assume, for the sake of our arguments, that there was a period in which systems capable of using signs didn't exist, or, to put it differently, that semiotic systems arose at some point in the course of evolution. Notice that this doesn't mean we are taking any stance as regards the possibility that signs may have in some sense preceded such systems. What we are proposing is that, before the emergence of semiotic systems, only reactive systems existed, which were not capable of using signs. By referring to 'reactive systems', we mean that, surely, there were things in the world to which physically embodied natural systems reacted, but these systems were not yet able to use something as a sign for something else. Based on these arguments, we will say that semiotic systems constitute a new class of systems, with a new kind of structure, capable of producing and interpreting signs, and, thus, realizing semiosis, as an emergent process.

\footnotetext{
${ }^{3}$ About differences between naturalism and physicalism, see, e.g., Caro and MacArthur (2004).
} 
We also consider that, after the competence to handle signs and instantiate semiosis emerged, the evolution of semiotic systems obviously didn't cease, but different, new kinds of such systems emerged, operating with different classes of signs (iconic, indexical, symbolic) and evolving in different manners.

Another characteristic of emergence theories is the thesis of synchronic determination, a corollary of physical monism: A system's properties and behavioral dispositions depend on its microstructure, i.e., on its parts' properties and arrangement. From this dependence, synchronic determination follows, namely, the idea that there can be no difference in systemic properties and dispositions without there being some difference in the properties of the system's parts and/or in their arrangement. We should consider, thus, whether semiosis is synchronically determined by the properties and arrangement of the parts underlying such a process.

To deal with this issue, we should examine the relationship between chains of triads and individual triads. It is clear, from the Peircean framework, that all kinds of semiosis are synchronically determined by the microstructure of the individual triads composing a chain of triads, i.e., by relational properties and arrangement of the elements S, O, and I.

These ideas are sufficient for the proposal of a weak emergentist account of semiosis. By 'weak', we mean that it would be compatible with reductionism, i.e., a methodological and epistemological position committed to the idea that knowledge about the parts of a system and their properties is enough to understand the global behavior of the system as a whole. Emergentists, however, usually aim at non-reductionist accounts, which characterize strong emergence theories. A strong emergentist account demands at least one of two notions: irreducibility and unpredictability. ${ }^{4}$

Stephan $(1998,1999)$ distinguishes between two kinds of irreducibility. ${ }^{5}$ The first one is based on the behavioral unanalyzability of systemic properties:

$\left(\mathrm{I}_{1}\right)$ [Irreducibility as unanalyzability] Systemic properties which cannot be ana-

lyzed in terms of the behavior of a system's parts are necessarily irreducible.

This notion plays an important role in debates about phenomenal qualities of human subjective experience (qualia), often regarded to be irreducible because they are allegedly intrinsic properties, capable of being experienced only 'from within', and, thus, couldn't be adequately characterized in terms of the macroscopic or microscopic behavior of the nervous system's parts (e.g., Levine, 1983; Kim, 1998).

A second notion of irreducibility is based on the non-deducibility of the behavior of the system's parts:

$\left(\mathrm{I}_{2}\right)$ [Irreducibility of the behavior of the system's parts] a systemic property will be irreducible if it depends on the specific behavior the components show in

\footnotetext{
${ }^{4}$ On 'irreducibility' and 'unpredictability' of emergence, see also Salthe (1993).

${ }^{5}$ For a related distinction, between vertical and horizontal conditions for emergence, see Boogerd et al. (2005). We will not consider it here for reasons of space. For a treatment in the context of semiotics, see Queiroz and El-Hani (2006).
} 
a system of a given kind, and this behavior, in turn, does not follow from the components' behavior in isolation or in other (simpler) kinds of system. ${ }^{6}$

El-Hani and Queiroz (2005) offer an example which illustrates the basic ideas in this notion of irreducibility. Consider, first, that mitotic division $(M)$, for instance, is a systemic property which is synchronically determined by a specific kind of microstructure, $W$ (involving, among other structures, spindle fibers). It is, therefore, a property observed at the level of systems of the kind $S$, as a whole, and depends on the behavior shown by its components.

The second step, then, is to argue that this property cannot be inferred from how cell components behave in simpler kinds of systems. Let us consider a different kind of cell division, binary fission, $B$, synchronically determined by a different kind of microstructure, $R$, observed in systems of a different kind, $S$ '. Consider, also, that $S^{\prime}$ is a class of simpler systems, as compared to systems classified in $S$. For the sake of our arguments, we will simply consider a putative measure of complexity based on (i) the number of elements composing a system, and (ii) the number of interactions between these elements. ${ }^{7}$

The distinction between modes of irreducibility entails that a claim that a given property, process etc. is reducible or irreducible needs more qualification, since it is plausible that, say, a property is 'reducible' in a particular sense, while it is 'irreducible' in another sense. In our example, we can say that $M$ is reducible to $W$ in the sense of its analyzability: if we know the properties and relations of the cell components within systems of the class $S$, instantiating structure $W$, the relevant laws of nature and the required composition principles, we will be able to infer that systems of kind $S$ exhibit property $M$. Therefore, we will be able to inductively predict that, and deductively explain why, $S$ exhibits $M$.

To examine, then, if $M$ is irreducible in terms of its non-deducibility, we should ask whether the behavior of $S$ 's parts, which instantiate $M$ when related as they are in structure $W$, can be inferred from their behaviors in simpler systems, say, included in class $S^{\prime}$ ' and instantiating $R$. What we know about the biological example we are addressing plausibly indicates that $M$ is very likely to be irreducible in this sense. Therefore, even if we know everything there is to be known about the properties of the parts and the structure of systems of class $S$, we will be unable to infer how those parts would behave in systems of class $S$, in the absence of specific knowledge about micro-structure $W$. If we cannot infer how the parts behave in $S$, we will not be capable of predicting or explaining the emergent properties those parts will realize in $S$, including $M$.

According to this argument, mitosis is irreducible in the sense of non-deducibility, even though it is reducible in the sense of its analyzability. We believe that emergent properties of biological systems often show these characteristics. This is why the distinction

\footnotetext{
${ }^{6}$ It is here that the idea of downward causation (DC) can enter the scene. We will not deal with the problem of DC here, for reasons of space.

${ }^{7}$ It is surely rather controversial what complexity is and how it should be measured (see, e.g., Adami, 2002). We are only using this rather crude notion of complexity for the sake of our arguments. We don't think the main thrust of our arguments would change if we employed a different account of complexity.
} 
between modes of irreducibility is rather consequential to discussions about reductionism in biology.

Let us now turn to the basic Peircean idea of the irreducibility of semiotic relations. These relations are regarded by Peirce as irreducible in the sense that they are not decomposable into any simpler relation (CP 5.484). Thus, the semiotic relation is not irreducible because the condition of analyzability is violated. Given synchronic determination, from the behavior of the elements of a triad it must follow the properties the triad possesses, including the very property of being a semiotic process. A semiotic relation is irreducible for its non-deducibility. The specific behavior of the elements of a triad is irreducible because it does not follow from the elements' behavior in simpler relations. According to Peirce, if we consider only a dyadic relation, S-I, S-O or I-O, or an element of a triad in itself, we will not be able to deduce how they would behave in a triadic relation, S-O-I (EP 2:391). We should also bear in mind that, even though Peirce classified signs on the basis of the sign-object relation, icons and indexes are not less triadically-dependent than symbols. After all, they all depend crucially on the communication of a form from O to I through $S$, as argued above. ${ }^{8}$

Strong emergence theories can also be based on the claim that emergent properties or structures are "in principle theoretically unpredictable". An idea of "genuine novelty" then enters the scene: a genuinely new property or structure cannot be theoretically predicted before its first appearance. A systemic property can be unpredictable in this sense for two different reasons (Stephan, 1998): (i) because the microstructure of the system exemplifying the property for the first time is unpredictable; (ii) because it is irreducible, and, in this case, it doesn't matter if the system's microstructure is predictable or not. The second case offers no additional gains beyond those obtained in the treatment of irreducibility. For this reason, we will focus on the first condition. The structure of triads and chains of triads can be regarded as in principle theoretically unpredictable based on the Peircean view that an element of indeterminism, spontaneity, and absolute chance is present in the natural world. On the grounds of this basically metaphysical approach, the microstructure of semiotic systems can be regarded as unpredictable, and, consequently, the same can be said of semiosis, as an emergent process of these systems. ${ }^{9}$

Based on these arguments, we are in a position to conclude that a strong emergence theory can be advocated in the case of semiotic phenomena. This theory can be based on a concept of irreducibility based on the non-deducibility of the behavior of signs, objects, and interpretants in semiotic relations from their possible behaviors in simpler relations, and/or on a concept of theoretical unpredictability of the structure of semiotic systems.

\footnotetext{
${ }^{8}$ Semiotic processes can also be said to be non-deducible, and, thus, irreducible, because they depend on the embedment of particular triads in chains of triads and networks of chains of triads, as explained in the next section.

${ }^{9}$ Notice that the two reasons for the unpredictability of systemic properties have very different status. While the second is empirical in nature, particularly if irreducibility is interpreted in terms of non-deducibility, the claim of in principle theoretically unpredictability in the Peircean framework, at least as explained above, depends on a metaphysical approach committed to fundamental indeterminism, which a thinker can clearly reject.
} 
After this attempt to make it more precise the claim that semiosis is an emergent process, we will discuss in the next section a model to explain how semiotic processes emerge in semiotic systems.

\section{A GENERAL MODEL OF THE EMERGENCE OF SEMIOSIS}

Salthe (1985) put forward an approach called "hierarchical structuralism" as a means for developing a coherent and heuristically powerful way of representing entities in nature. A fundamental element in this approach is his "basic triadic system", clearly influenced by Peirce. This system aims at discovering general rules and principles of constraint within which laws of nature must operate.

According to the basic triadic system, to describe the fundamental interactions of a given entity or process in a hierarchy, we need (i) to consider it at the level where we actually observe it (focal level); (ii) to investigate it in terms of its relations with the parts described at a lower level (usually, but not necessarily always, the next lower level); and (iii) to take into account entities or processes at a higher level (also usually but not always the next higher level), in which the entities or processes observed at the focal level are embedded. Both the lower and the higher level have constraining influences over the dynamics of the entities and/or processes at the focal level. These constraints allow us to explain the emergence of entities or processes (e.g., semiosis) at the focal level.

In a manner which is consistent with Peircean pragmatism, the choice of the focal, lower, and higher levels depends on the research goals. Therefore, it results from a decision made by a researcher on the grounds of the theoretical framework and methodological approach. The theoretical and methodological bases chosen by a researcher, in turn, are partly (and, often, strongly) determined by the epistemic practices accepted as scientifically adequate and, typically, also standardized by the scientific community.

At the lower level, the constraining conditions amount to the "potentialities" or "initiating conditions" for the emergent process, while constraints at the higher level are related to the role of a (selective) environment played by the entities at this level, establishing the boundary conditions that coordinate or regulate the dynamics at the focal level. The regulation of a focal-level process by higher-level boundary conditions is interpreted here as a kind of selective process. ${ }^{10}$

In this model, an emergent process at the focal level is explained as the product of an interaction between processes taking place at lower and higher levels. The phenomena observed at the focal level should be ". . . among the possibilities engendered by permutations of possible initiating conditions established at the next lower level" (Salthe, 1985, p. 101). But processes at the focal level are embedded in a higher-level environment that plays a role as important as that of the lower level and its initiating conditions. Through the temporal evolution of systems at the focal level, this environment or context selects

\footnotetext{
${ }^{10}$ Suppose that the causal relation between a given element of a system, A, and another element of the same system, B, is regulated. This is understood, in this framework, as the selection of $\mathrm{B}$ as the most probable effect of A, among other possible effects, by boundary conditions established by a level higher to the level where the causal relation at stake is taking place. This is related to ideas found in Polanyi (1968), who introduced the term "boundary conditions" in biology, and Campbell (1974).
} 
among the states potentially engendered by the components those that will be effectively actualized. As Salthe (id. ibid.) puts it, "what actually will emerge will be guided by combinations of boundary conditions imposed by the next higher level".

Semiotic processes at the focal level are described here as chains of triads. We can address, then, the interaction between semiosis at the focal level, potential determinative relations between elements at the lower level (micro-semiotic level), and networks of semiotic processes at the higher level (macro-semiotic level).

The micro-semiotic level concerns relations of determination that may take place within each triad S-O-I. These relations provide the way the elements in a triad are arranged in semiosis. According to Peirce, the interpretant is determined by the object through the mediation of the sign (I is determined by $\mathrm{O}$ through $\mathrm{S}$ ) (MS 318:81). This is a result from two determinative relations: the determination of the sign by the object relatively to the interpretant ( $\mathrm{O}$ determines $\mathrm{S}$ relatively to $\mathrm{I}$ ), and the determination of the interpretant by the sign relatively to the object ( $\mathrm{S}$ determines I relatively to $\mathrm{O}$ ) (see Figure 2).

We consider that, given the relative positions of $\mathrm{S}, \mathrm{O}$, and $\mathrm{I}$, a triad $\mathrm{t}_{i}=\left(\mathrm{S}_{i}, \mathrm{O}_{i}, \mathrm{I}_{i}\right)$ can only be defined as such in the context of a chain of triads $T=\left\{\ldots, t_{i-1}, t_{i}, t_{i+1}, \ldots\right\}$ (see Gomes et al., 2003, 2005). This is a consequence of an idea discussed above, namely, that semiosis entails the instantiation of chains of triads (See Figure 1).

At the macro-semiotic level, networks of chains of triads which embed the semiotic process at the focal level are described. Focal-level semiosis will emerge as a process through the interaction between micro- and macro-semiotic processes, i.e., between the relations of determination within each triad and the embedment of each individual chain in a whole network of sign processes.

To proceed with the argument, we should consider a distinction made by Peirce as regards the nature of the object:

"We must distinguish between the Immediate Object - i.e., the Object as represented in the sign - and [...] the Dynamical Object, which, from the nature of things, the Sign cannot express, which it can only indicate and leave the interpreter to find out by collateral experience" (CP 8.314. Emphasis in the original.

See also EP 2.498).

The immediate object of a sign is the object as it is immediately given to the sign, the dynamical object in its semiotically available form. The dynamical object, in turn, is a real thing which the sign can only indicate, and the interpreter should find out by its experience.

Each chain of triads always indicates the same dynamical object, through a series of immediate objects, as represented in each triad. The potentialities of indicating a dynamical object are constrained by the relations of determination within each triad. That is, the way $\mathrm{O}$ determines $\mathrm{S}$ relatively to $\mathrm{I}$, and $\mathrm{S}$ determines I relatively to $\mathrm{O}$, and then how $\mathrm{I}$ is determined by $\mathrm{O}$ through $\mathrm{S}$ leads to a number of potential ways in which a dynamical object may be indicated in focal-level semiosis, i.e., to a set of potential triadic relations between immediate objects, signs, and interpretants.

When developing such a model, we should also consider a distinction between potentiality and actuality, introducing the definitions of potential signs, objects, and interpretants. A potential sign is something that may be a sign of an object to an interpretant, i.e., it may stand for that object to an interpretant. A potential object is, in turn, something 
that may be the object of a sign to an interpretant. And, finally, a potential interpretant is something that may be the interpretant of a sign, i.e., it may stand for that sign. The micro-semiotic level is the domain of potential signs, objects, and interpretants.

We should consider, then, a whole set $W$ of potential determinative relations between these three elements, which can generate, in turn, a set of potential triads. These triads cannot be fixed, however, by the micro-semiotic level, which establishes only the initiating conditions for chains of triads at the focal level. To fix a chain of triads, and, consequently, the individual triads which are defined within its context, boundary conditions established by the macro-semiotic level should also play their selective role, which is required for the actualization of potential chains of triads. After all, according to this model, chains of triads are actualized at the focal level by a selection of those triads that will be effectively actualized amongst those potentially engendered at the microsemiotic level. As we saw above, a triad $t_{i}=\left(\mathrm{S}_{i}, \mathrm{O}_{i}, \mathrm{I}_{i}\right)$ cannot be defined atomistically, in isolation, but only when embedded within higher-level structures and/or processes, including both chains of triads $T=\left\{\ldots, t_{i-1}, t_{i}, t_{i+1}, \ldots\right\}$ and networks of chains of triads $\mathrm{ST}=\left\{T_{1}, T_{2}, T_{3}, \ldots, T_{n}\right\}$.

Considering the dynamics of semiotic processes at the focal level, we can say that their temporal evolution is determined by events of actualization of potential chains of triads and potential triads. Triads are actualized, realizing a specific chain at the focal level, through the operation of two constraints. First, potential determinative relations (initiating conditions) at the micro-semiotic level constrain the universe of potential chains of triads, given that the whole set $W$ of possible determinative relations between potential signs, objects, and interpretants is always smaller than the universe $U$ of all potentially existent triads. That is, given the initiating conditions established at the micro-semiotic level, a given chain of triads realized at time $t$ will be among the elements of a set $W=U-x$ of potential chains of triads that might be actualized at $t .{ }^{11}$ Then, a second kind of constraint acts on the set $W$, namely, boundary conditions established by the macro-semiotic level, in the context of which a given chain of triads will be effectively realized. The boundary conditions will select, among all the potential chains of triads which could be realized from the set $\mathrm{W}$ of potential determinative relations S-O-I, a specific chain $T_{i}=\left\{\ldots, t_{i-1}, t_{i}, t_{i+1}, \ldots\right\}$ to be actualized at $t$.

It is in this sense that the emergence of semiotic processes at the focal level, in which chains of triads are actualized, is explained in this model as resulting from an interaction between potentialities established by the micro-semiotic level and the selective, regulatory influence of the macro-semiotic level. This model can be applied to iconic, indexical, and symbolic semiotic processes. The crucial difference is that forms will be communicated from objects to interpretants through signs as patterns of similarity, spatiotemporal correlations, and law-like relationships, respectively.

This model also shows that semiotic processes are irreducible because of its nondeducibility, since they depend both on the potential determinative relations between elements in a triad, which cannot be deduced from dyadic relations or from how an

\footnotetext{
${ }^{11} \mathrm{By}$ ' $x$ ' we mean here those potentially existent triads which are elements of $U$ but are not realizable in a given set of natural worlds, among all the conceivable worlds (which compose a set of all logically possible worlds), and, therefore, are not elements of $W$.
} 
element of a triad behaves in itself, and on boundary conditions established by a network of semiotic processes.

In this section, our general model of the emergence of semiosis was presented in rather abstract terms. We will now move to a brief but concrete case study which aims at illustrating and further elucidating the basic tenets of the model.

\section{APPLYING THE MODEL TO INTERPRET A SEMIOTIC PROCESS IN B-CELLS}

We previously employed the model presented in the previous section to address some semiotic processes in the genetic information system, namely, transcription and translation (El-Hani et al., 2006, forthcoming). Here, we will not refer to this previous study, but rather move on to a discussion of some basic ideas for applying this model to the investigation of another set of semiotic processes, related to signal-transduction in centrally important cellular processes in the immune system, as, for instance, B-cell activation.

B-cells possess a membrane receptor, the B-cell receptor (BCR), which has two functions in B-cell activation (Pierce, 2002): it initiates signal cascades that result in changes in gene expression patterns in B-cells and other processes involved in activation; and it plays a role in the uptake and processing of antigens to be presented to other key class of cells in the immune system, T-helper cells (see Figure 8).

The semiotic process we wish to briefly analyze here concerns the initiation of step (b) in Figure 8, namely, the transcriptional activation of genes by a signal-transduction cascade triggered by BCR. This process is initiated by the binding of antigens to BCR. The antigen is a sign which stands for something else, say, a virus-infected cell. BCR acts as an interpreting system in the cell membrane, and triggers processes by means of which interpretants are produced inside the B-cell (Figure 9). The intepretant in this case is the phosphorylated state of $\mathrm{BCR}$, which becomes, in turn, itself a sign standing for the virus-infected cell. This generates a new triad, linked to the previous one by the double role played by the phosphorylated state of BCR, which is both the interpretant of a first triad, and a sign of a second triad. The binding of a kinase called Syk (as a signal manager, see Reth \& Wienands, 1997) to the phosphorylated BCR makes a specific interpretative process proceed. When Syk is activated, it leads to the activation of another enzyme, phospholipase $\mathrm{C} \gamma$, which converts the membrane component phosphatidylinositol 4,5biphosphate into the two second messengers diacylglycerol (DAG) and inositol 1,4,5triphosphate (IP3). DAG recruits and activates the cytosolic protein kinase C (PKC). IP3 binds to receptors on the endoplasmic reticulum, causing the release of $\mathrm{CA}^{2+}$ ions ( Reth \& Wienands, 1997). The object is the same, but the interpretant of the second triad is DAG or IP3, depending on which signal-transduction cascade we are modeling. Now, DAG and IP3 stand for the virus-infected cell, and act as signs to a subsequent triad. In these terms, the signal-transduction cascades correspond to particular semiotic processes, interpreted in accordance with our model as chains of triads at the focal level which indicates the same dynamic object throughout.

This process can be analyzed in more detail, as sketched above, or seen from a global view. From this latter standpoint, we can analyze the overall result of the semiotic process at stake as a triad including the antigen as a sign, the virus-infected cell as an object, and the activation of a particular set of genes through a signal-transduction cascade as 


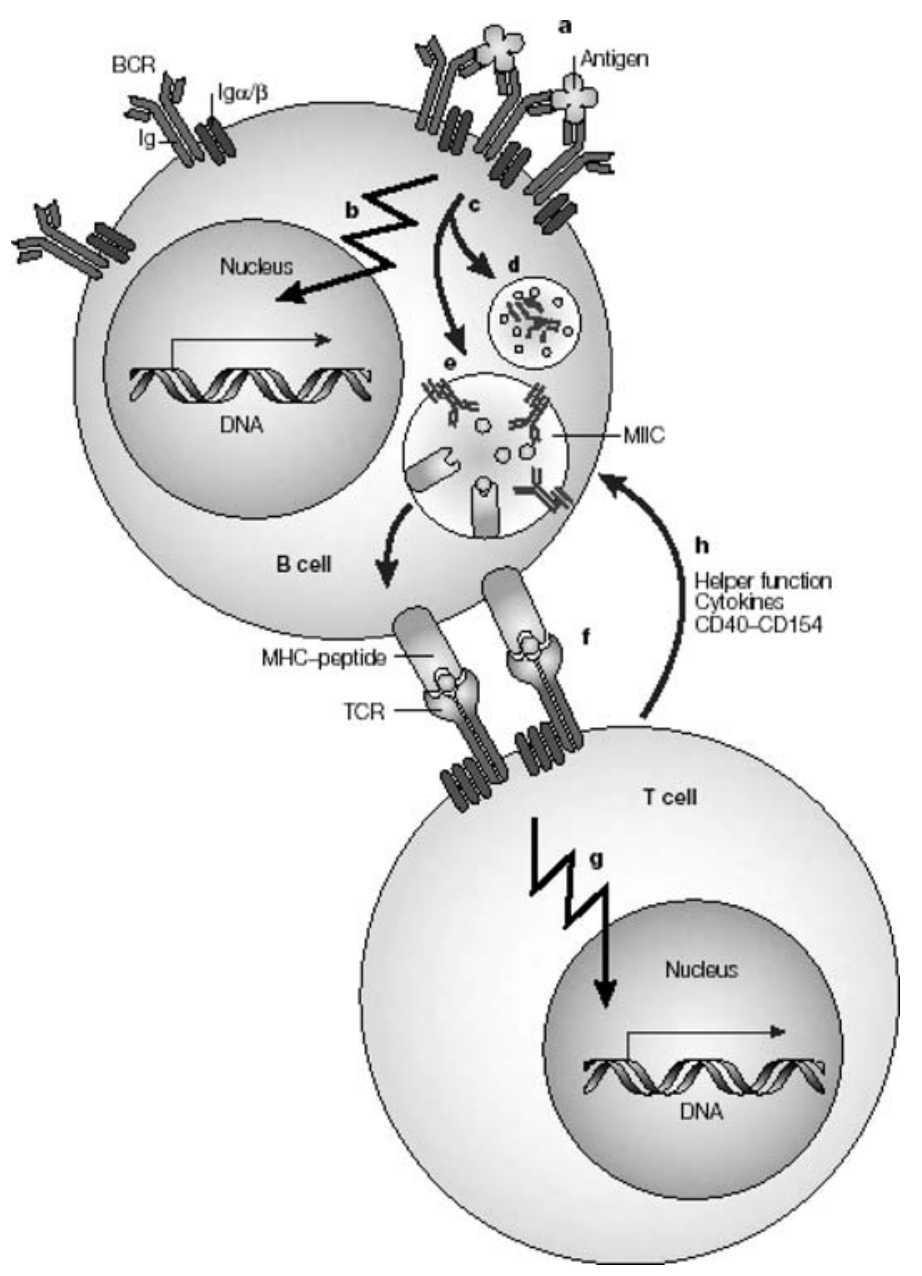

Figure 8. The functions of BCR in B-cell activation. Following antigen binding (a), the B-cell receptor (BCR) triggers a signal-transduction cascade (b), which regulates the transcription of genes associated with B-cell activation. BCR is internalized (c) and either degraded (d) or trafficked to an intracellular compartment (MIIC) (e), where complexes containing the antigen bound to BCR are formed. These complexes are transported to the cell surface, where they are recognized by the T-cell receptor (TCR) of T-helper cells ( $\mathrm{f}$ ), leading to T-cell activation ( $\mathrm{g}$ ), by triggering another signal-transduction cascade. The activated T cell provides 'help' to the B cell, leading to full B-cell activation (h). Ig, immunoglobulin. (From Pierce, 2002).

an interpretant. We regard this sign process as an indexical one, since the antigen (as a sign) and the virus-infected cell (as the object of that sign) are connected through a physical (indeed, causal) correlation. Therefore, the form which is communicated from the object to the interpretant through the sign in this semiotic process is a general physical (causal) correlation between a virus-infected cell and the presence of a given antigen in its surface. 


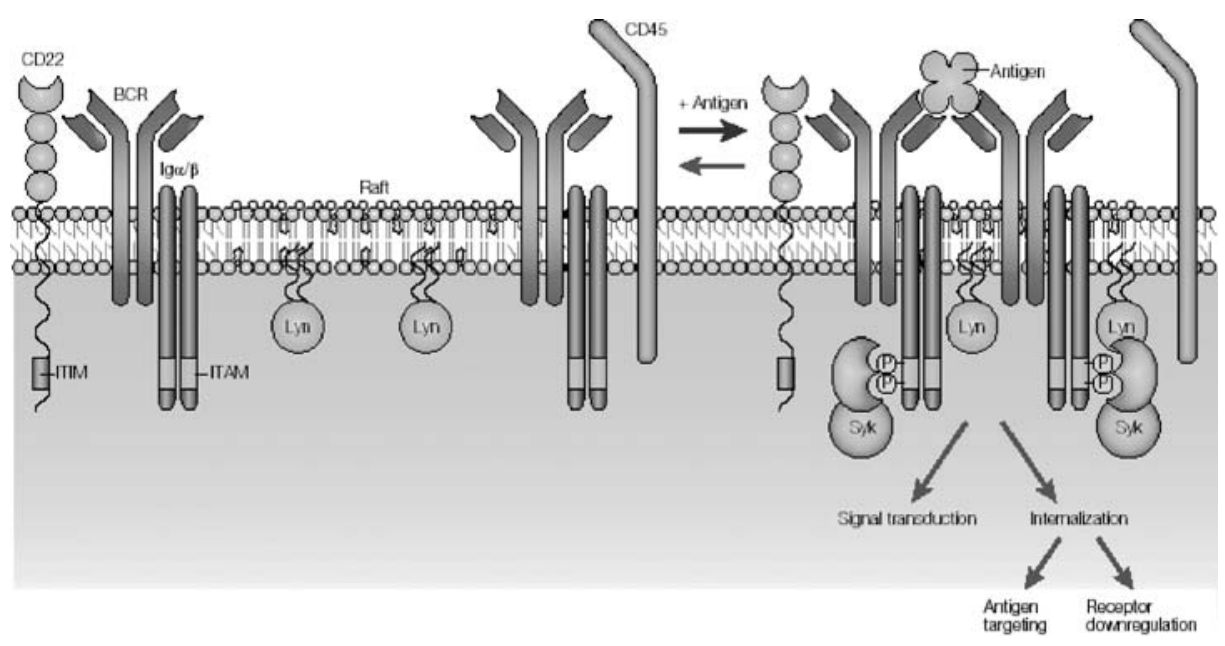

Figure 9. Model of the initiating events in the signal-transduction cascade leading to B-cell activation. In resting B cells, BCR is excluded from membrane domains which concentrate an enzyme which catalyzes phosphorylation reactions, the Src-family kinase Lyn. In the absence of antigen, the BCR monomer has a weak affinity for the membrane domains, but antigen binding makes BCR molecules associate with each other, increasing affinity for the domains. Stable residency in the domains results in association with Lyn, which phosphorylates the BCR, recruiting another kinase, named Syk, and initiating the signaling cascade. (From Pierce, 2002).

The micro-semiotic level amounts to the potential relations between signs, objects, and interpretants in the B-cell and its environment. For instance, a given antigen is a potential sign for a virus-infected cell while it is not recognized and bound by BCR. When this binding takes place, an actualization process begins, by means of which that potential sign will become a sign in effective action, standing for a virus-infected cell to the immune system, which will use this sign as a mediating element in the interpretation of its environment, and this, in turn, may eventually lead to the protection of the organism from some virus disease. A particular gene expression pattern at the B-cell genome can be treated, in turn, as a potential interpretant, which will be actualized as a result of a signaling cascade initiated by the antigen, as a sign. ${ }^{12}$

The macro-semiotic level, in turn, corresponds to a network of signaling processes which are ultimately involved in B-cell activation. To explain it in a more precise way, we should consider two features. The first is shown in Figure 10. As explained above, in our model the macro-semiotic level amounts to a network of chains of triads in which a particular chain (a particular semiotic process) is embedded. Notice, first, that initiation of signaling in the BCR pathway in B-cell activation is not triggered by one BCR molecule alone, but rather by several molecules in a quite organized manner (Figure 10).

\footnotetext{
${ }^{12}$ For more details on the interpretation of gene expression as a passage from potentiality to actuality, see El-Hani et al. (forthcoming[a,b]).
} 


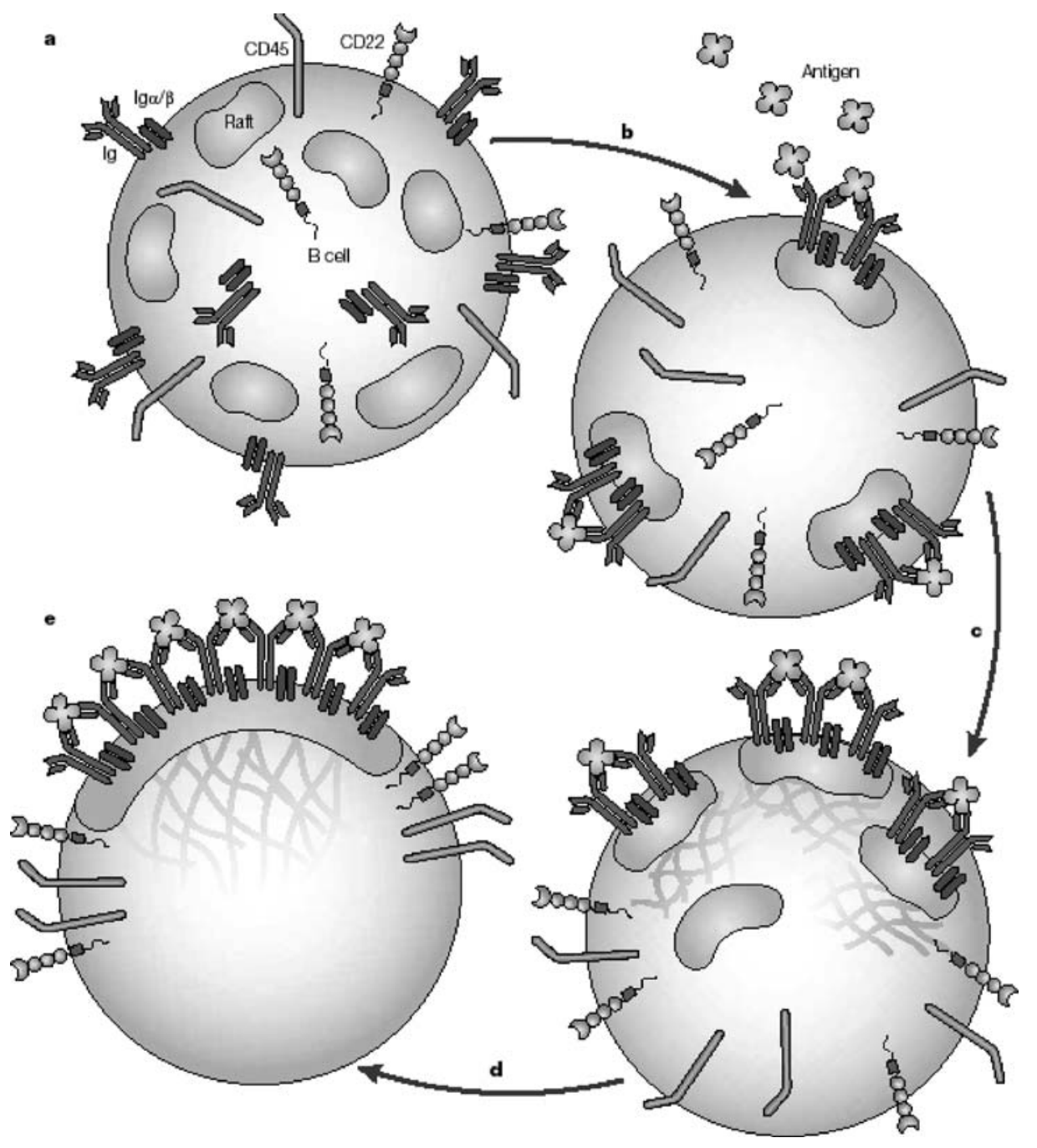

Figure 10. Initiation of signaling by several BCR molecules. In resting B cells, the B-cell receptor (BCR) is excluded from membrane domains (a). After antigen binding, BCR associates with membrane domains, as shown in Figure 9 (b). The above figure shows, in turn, that several signal-transduction cascades are initiated at the same time. Signaling is initiated in membrane domains, leading to the assembly of signaling complexes. The initiation of signaling promotes a clustering of the membrane domains (c). Clustering continues as the clustered domains are moved to one pole of the cell (d). (From Pierce, 2002).

Therefore, it is not the case that only one chain of triads, i.e., one semiotic process, will lead to B-cell activation. Rather, several signal-transduction cascades will occur at the same time, each corresponding to a semiotic process, and ultimately leading to the actualization of a set of genes involved in B-cell activation. 


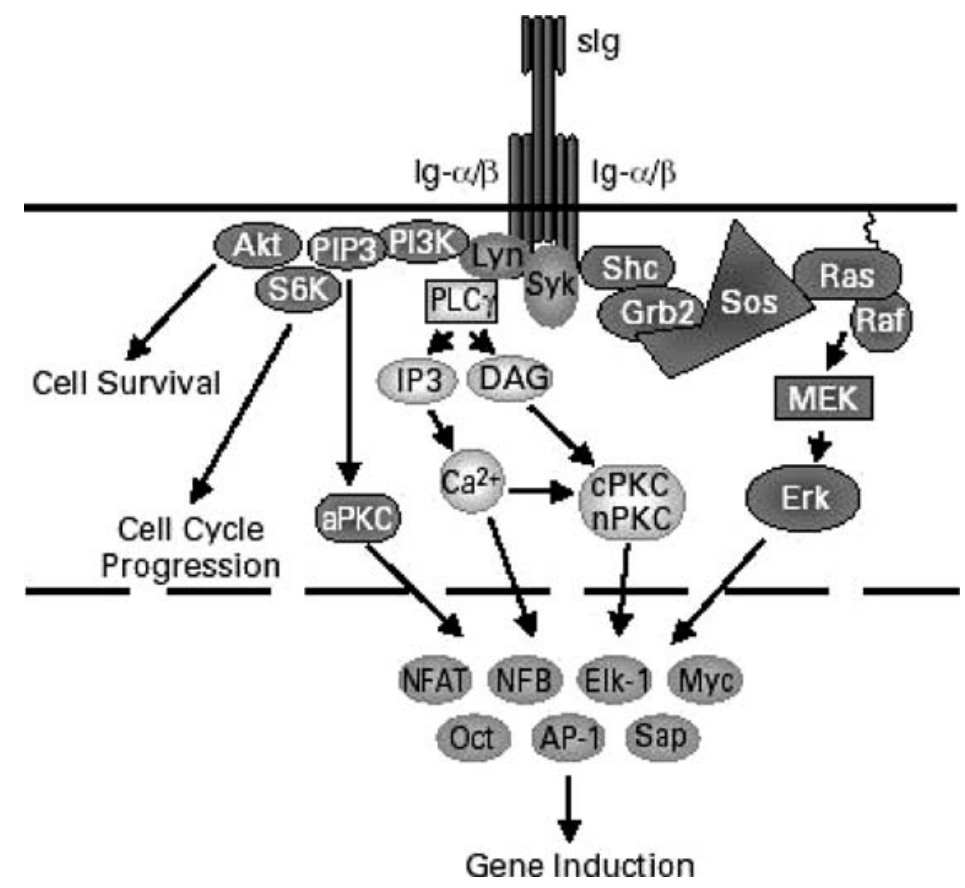

Figure 11. Intracellular signaling pathways initiated by cross-linking of B-cell receptors by antigen (From Goodridge \& Harnett, 2005).

But we should go beyond this feature, since one might counter-argue by saying that it does not really correspond to a network of signaling processes, and could be rather described as a series of linear, unconnected chains of triads. Although it is beyond the scope of this paper to analyze the several steps in it, Figure 11 intends to show that there is indeed a network of signaling processes involved in the B-cell antigen receptor pathway, since several intracellular signal-transduction cascades are triggered by crosslinking of BCR by antigens. After the activated BCR complex is formed, a signaling scaffold forms around it with recruitment of adaptors and other signaling proteins. This will trigger the activation of several different cascades, including MAP kinase, PI3K and PLC $-\gamma$ pathways, among others. These pathways will lead to changes in the gene expression pattern in the B-cell, B-cell survival and proliferation (Goodridge \& Harnett, 2005). What our model suggests is that a macro-semiotic environment selects among the potential signaling pathways that can be triggered by BCR, specific signaling pathways to be initiated by particular signal managers (Reth \& Wienands, 1997).

In accordance with the model developed here, the actualization of chains of triads corresponding to each signal-transduction cascade can be treated as an emergent process resulting from an interaction between initiating conditions at a micro-semiotic level containing potential signs (antigens), objects (non-self entities in an organism, to which its immune system can respond), and interpretants (particular gene expression patterns in the B-cell genome), and boundary conditions established by a network of signaling 
events at a macro-semiotic level, both within and between particular cells in the immune system.

Our intention here was just to offer some basic ideas for applying the model explained above to semiotic processes in the immune system. This is a biological system particularly suitable to semiotic analyses. After all, the immune system is a recognition apparatus, and, thus, has necessarily to play an interpretative role. This analysis will be extended in future works. For the moment being, we hope this section provided some insight into the heuristic role of the model developed here in the analysis of specific semiotic processes.

The general ideas involved in the model of the emergence of semiosis presented in this paper are shown in Figure 12, using the analysis of signal-transduction in B-cell activation as an example.

\section{CONCLUSION}

In this paper, we examined some theoretical constraints one must consider to clearly describe the dynamics responsible for the emergence of semiosis in an evolutionary and developmental scenario. We drew on Salthe's hierarchical structuralism to propose a model to explain the emergence of semiosis in semiotic systems. According to this model, semiosis is conceived as a systemic process at a focal level, in which chains of triads are instantiated as a result of the interaction between potentialities established by a micro-semiotic level (initiating conditions) and the regulatory, selective influence of a macro-semiotic level (boundary conditions).

We believe this model can play a heuristic role in the development of explanations for specific semiotic processes, as we illustrated by advancing some ideas about a semiotic process in the immune system, namely, B-cell activation. Researchers in philosophy of biology and theoretical biology often face an important question when addressing empirical scientists: after all, what contribution do all these concepts, theories and models bring to our understanding of living systems ? $^{13}$ The treatment of the B-cell activation process presented above has not generated new hypotheses yet (even though this is an important result to seek in the future). But we consider that there is another role for theoretical treatments, namely, to offer new explanations to biological concepts, a task which is particularly important when there are gaps in the conceptual structure of biology. This science has been swamped by information talk since the 1950s (see, e.g., Kay, 2000), but there is no established theoretical framework to deal with concepts related to this talk, such as information itself, or code, or signaling, for that matter. We see the present paper as an attempt to contribute to a clearer understanding of what we can mean by treating mechanistic relations in a cell as signaling pathways and networks. To mean something clear and precise, we should embed these notions in a proper theoretical framework. Peircean semiotics is an important candidate to this framework, and we should strive for addressing it, as we attempted to do in this paper.

\footnotetext{
${ }^{13}$ Two referees who examined our paper raised this relevant issue. As Cariani (personal communication) comments, it is always a difficult and provocative question to answer.
} 


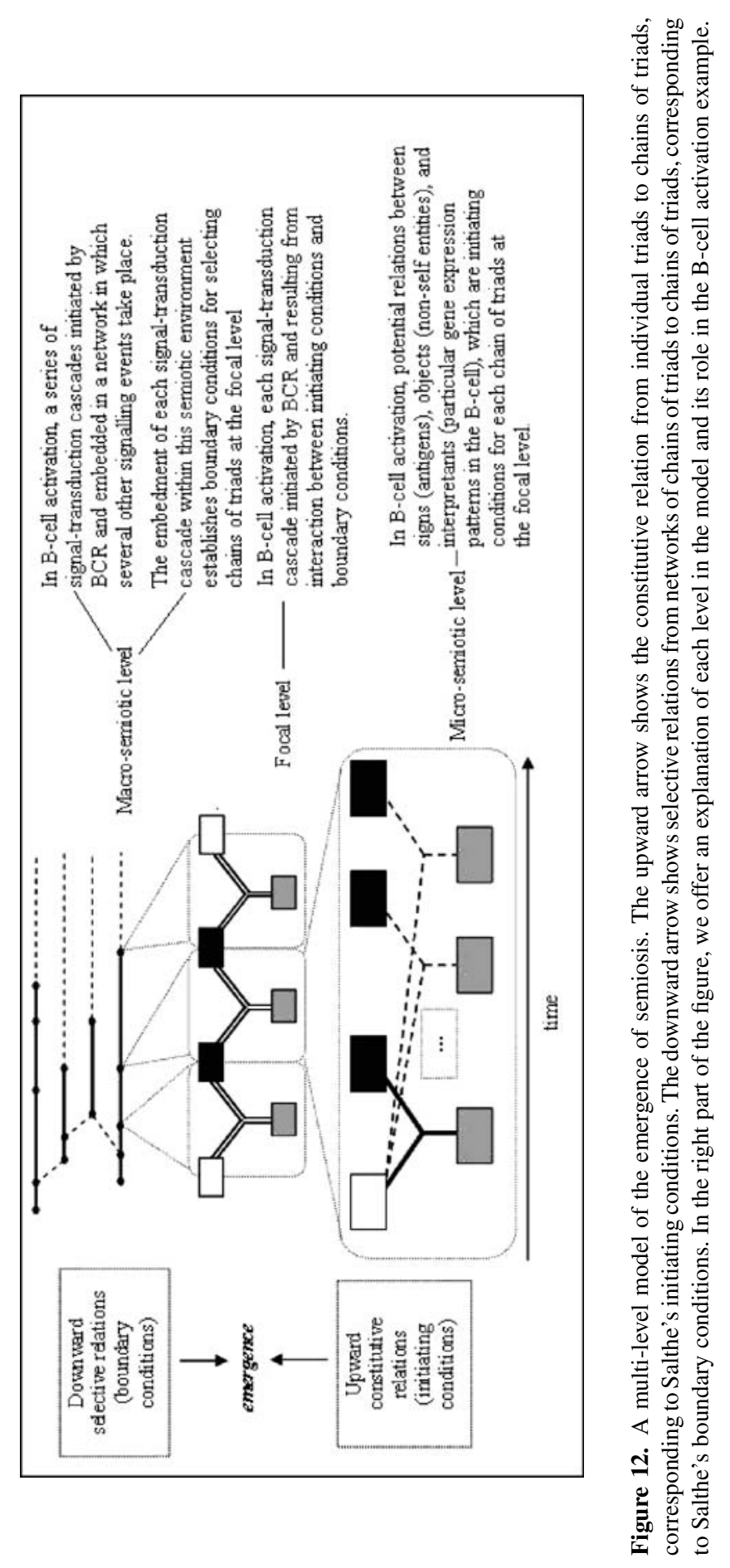




\section{ACKNOWLEDGEMENTS}

We are indebted to Tony Chemero, Peter Cariani, and anonymous reviewers of our paper for his insightful comments, which were very helpful in the preparation of the final manuscript. J.Q. thanks The State of São Paulo Research Foundation (FAPESP). C.N.E.H. thanks the Brazilian National Research Council (CNPq).

\section{REFERENCES}

Adami, C. (2002). What is complexity? Bioessays 24: 1085-1094.

Adami, C. (2004). Information theory in molecular biology. Physics of Life Reviews 1: 3-22.

Banathy, B.A. (1998). An information typology for understanding living systems. BioSystems 46 : 89-93.

Bedau, M. (2002). Downward causation and autonomy of weak emergence. Principia 6(1): 5-50.

Bergman, M. (2000a). Reflections on the role of the communicative sign in semeiotic. Transactions of the Charles S. Peirce Society: A Quarterly Journal in American Philosophy, Spring, XXXVI(2): 225-254.

Bergman, M. (2000b). Meaning and Mediation: Toward a communicative interpretation of Peirce's theory of signs. Yliopistopaiano, Helsinki.

Blitz, D. (1992). Emergent Evolution: Qualitative Novelty and the Levels of Reality. Kluwer, Dordrecht.

Boogerd, F.C., F.J. Bruggeman, R.C. Richardson, A. Stephan and H. Westerhoff (2005). Emergence and its place in nature: A case study of biochemical networks. Synthese 145(1): 131-164.

Campbell, D.T. (1974). Downward Causation in Hierarchically Organised Biological Systems. In: Ayala, F. and Dobzhansky, Th. (Eds.). Studies in the Philosophy of Biology: Reduction and Related Problems, pp. 179-186. University of California Press, Berkeley.

Cariani, P. (1989). On the Design of Devices with Emergent Semantic Functions, PhD Dissertation, Department of Systems Science, State University of New York, Binghamton.

Cariani, P. (1991). Emergence and Artificial Life, Artificial Life II, In: Langton, C., Taylor, C., Farmer, J.D. and Rasmussen, S. (Eds.). SFI Studies in the Sciences of Complexity, Proc. Vol. X, pp. 775-797. Addison-Wesley, Redwood City, CA.

Cariani, P. (1998). Towards an evolutionary semiotics: The emergence of new sign-functions in organisms and devices. In: Van de Vijver, G., Salthe, S. and Delpos, M. (Eds.). Evolutionary Systems, Kluwer, Dordrecht, Holland, pp. 359-377.

Caro, M. and D. MacArthur (Eds.) (2004). Naturalism in Question. Harvard University Press, Cambridge-MA.

Cheney, D.L. and R. Seyfarth (1990). How Monkeys See the World. University of Chicago Press, Chicago.

Deacon, T. (1997). The Symbolic Species: The Co-evolution of Language and the Brain. W.W. Norton \& Company.

Deacon, T. (1999). Memes as signs. The Semiotic Review of Books 10(3): 1-3.

De Tienne, A. (2003). Learning qua semiosis. S.E.E.D. Journal - Semiotics, Evolution, Energy, and Development (3): 37-53. (available at http://www.library.utoronto.ca/see/pages/ SEED_Journal.html).

El-Hani, C.N. (2002). On the reality of emergents. Principia 6(1): 51-87.

El-Hani, C.N. and J. Queiroz (2005). Modos de irredutibilidade das propriedades emergentes, Scientiae Studia 3(1): 9-41.

El-Hani, C.N., J. Queiroz and C. Emmeche (2006). A semiotic analysis of the genetic information system. Semiotica 160(1/4): 1-68. 
El-Hani, C.N., J. Queiroz and C. Emmeche (forthcoming [a]). Genes, Information, and Semiosis. Tartu University Press (Tartu Semiotics Library), Tartu.

Emmeche, C. (1991). A semiotical reflection on biology, living signs and artificial life. Biology \& Philosophy 6(3): 325-340.

Emmeche, C. (1994). The Garden in the Machine: The Emerging Science of Artificial Life. Princeton University Press, Princeton.

Emmeche, C. (1997). Defining Life, Explaining Emergence, On-line: http://www.nbi.dk/ $\sim$ emmeche/ (Published in two parts as: Emmeche, C. 1997. Autopoietic Systems, Replicators, and the Search for a Meaningful Biologic Definition of Life, Ultimate Reality and Meaning 20: 244-264; Emmeche, C. 1998. Defining Life as a Semiotic Phenomenon, Cybernetics \& Human Knowing 5: 3-17).

Emmeche, C. (2003). Causal processes, semiosis, and consciousness. In: Seibt, J. (Ed.). Process Theories: Crossdisciplinary Studies in Dynamic Categories, Kluwer, Dordrecht. pp. 313336.

Emmeche, C. and J. Hoffmeyer (1991). From language to nature - the semiotic metaphor in biology. Semiotica 84(1/2): 1-42.

Fetzer, J.H. (1988). Signs and Minds: An Introduction to the Theory of Semiotic Systems. In: Fetzer, J. (Ed.). Aspects of Artificial Intelligence, pp. 133-161. Dordrecht, The Netherlands.

Fetzer, J.H. (1997). Thinking and computing: Computers as special kinds of signs. Minds and Machines 7: 345-364.

Freadman, A. (2004). The Machinery of Talk - Charles Peirce and the Sign Hypothesis. Stanford University Press, Stanford.

Gregersen, N.H. (Eds.) (2003). From Complexity to Life: On the Emergence of Life and Meaning. Oxford University Press, Oxford.

Gomes, A., R. Gudwin and J. Queiroz (2003). Towards Meaning Processes in Computers from Peircean Semiotics. S.E.E.D. Journal - Semiotics, Evolution, Energy, and Development 3(2): 69-79. On line: http://www.library.utoronto.ca/ see/pages/SEED_Journal.html.

Gomes, A., R. Gudwin and J. Queiroz (2005). Meaningful Agents: A Semiotic Approach. In: Thompson, C. and Hexmoor, H. (Eds.). Proceedings of the International Conference on Integration of Knowledge Intensive Multi-Agent Systems - Modeling, Evolution, and Engineering, Waltham, MA; IEEE Systems, Man and Cybernetics Society 1: 399404.

Goodridge, H.S. and M.M. Harnett (2005). Introduction to immune signalling. Parasitology 130: S3-S9.

Hoffmeyer, J. (1996). Signs of Meaning in the Universe. Indiana University Press, Bloomington, IN.

Hookway, C. (2002). Truth, Rationality, and Pragmatism - Themes from Peirce. Oxford University Press, Oxford.

Houser, N., D. Roberts and J. Evra (Eds.) (1997). Studies in the Logic of Charles Sanders Peirce. Indiana University Press, Indiana.

Hulswit, M. (2001). Semeiotic and the cement of the universe: A Peircean process approach to causation. Transactions of the Charles S. Peirce Society: A Quarterly Journal in American Philosophy, Summer, XXXVII(3): 339-363.

Jablonka, E. (1994). Inheritance systems and the evolution of new levels of individuality. Journal of Theoretical Biology 170: 301-309.

Jablonka, E. (2002). Information: Its interpretation, its inheritance, and its sharing. Philosophy of Science 69: 578-605.

Jablonka, E. and E. Szathmáry (1995). The evolution of information storage and heredity. Trends in Ecology and Evolution 10: 206-211. 
Jablonka, E., M.J. Lamb and E. Avital (1998). 'Lamarckian' mechanisms in Darwinian evolution. Trends in Ecology and Evolution 13: 206-210.

Kay, L.E. (2000). Who Wrote the Book of Life? A History of the Genetic Code. Stanford University Press, Stanford.

Kim, J. (1998). Mind in a Physical World: An Essay on the Mind-Body Problem and Mental Causation. MIT Press, Cambridge, Mass., and London.

Levine, J. (1983). Materialism and qualia: The explanatory gap. Pacific Philosophical Quarterly 64: 354-361.

Maynard Smith, J. (2000). The concept of information in Biology. Philosophy of Science 67(2): 177-194.

Maynard Smith, J. and E. Szathmáry (1995). The Major Transitions in Evolution. W.H. Freeman, Oxford.

Maynard Smith, J. and E. Szathmáry (1999). The Origins of Life: From the Birth of Life to the Origins of Language. Oxford University Press, Oxford.

Noble, W. and I. Davidson (1996). Human Evolution, Language and Mind. Cambridge University Press.

Nolfi, S. (2002). Power and limits of reactive agents. Neurocomputing 49: 119-145.

Nöth, W. (1994). Origin of semiosis. Sign Evolution in Nature and Culture. Mouton De Gruyter, Berlin.

Nöth, W. (2004). Semiogenesis in the evolution from nature to culture. In: Alac, M. and Violi, P. (Eds.). In the Beginning: Origins of Semiosis, Brepols, Turnhout. pp. 69-82.

Oyama, S. (2000). The Ontogeny of Information: Developmental Systems and Evolution, (2nd Ed). Cambridge University Press, Cambridge.

Peirce, C.S. (EP1, EP2). The Essential Peirce. Selected Philosophical Writings, Vol. 1 (1867-1893) (ed. by Houser, N. and Kloesel, C.). vol. 2 (1893-1913) (ed. by the Peirce Edition Project). Bloomington and Indianapolis: Indiana University Press, 1992 and 1998.

Peirce, C.S. (1931-1935). The Collected Papers of Charles Sanders Peirce. Electronic edition reproducing Vols. I-VI [Hartshorne, C. and Weiss, P. (Eds.). Cambridge: Harvard University Press, 1931-1935], Vols. VII-VIII [A.W. Burks (Ed.), same publisher, 1958]. Charlottesville: Intelex Corporation.

Peirce, C.S. (1967). In: Robin, R.S. (Ed.). Annotated Catalogue of the Papers of Charles S. Peirce. The University of Massachusetts Press, Massachusetts.

Pierce, S.K. (2002). Lipid rafts and B-cell activation. Nature Reviews Immunology 2: 96-105.

Pietarinen, A. (2005). Signs of Logic : Peircean Themes on the Philosophy of Language, Games, and Communication (Synthese Library, Vol. 329). Springer, Netherlands.

Polanyi, M. (1968). Life's irreducible structure. Science 160:1308-1312.

Queiroz, J. (2004). Semiose Segundo C.S. Peirce. EDUC, São Paulo.

Queiroz, J. and C.N. El-Hani (2006). Semiosis as an emergent process. Transactions of the Charles Sanders Peirce Society 42(1): 78-116.

Queiroz, J. and S. Ribeiro (2002). The biological substrate of icons, indexes and symbols in animal communication: A neurosemiotic analysis of Vervet monkey alarm-calls. In: Shapiro, M. (Ed.). The Peirce Seminar Papers - The State of the Art, Berghahn Books, New York, Vol. 5, pp. 69-78.

Ransdell, J. (1977). Some leading ideas of Peirce's semiotic. Semiotica 19(3/4):157-178.

Rescher, N. (1996). Process Metaphysics: An Introduction to Process Philosophy. State University of New York Press, New York.

Reth, M. and J. Wienands (1997). Initiation and processing of signals from the B cell antigen receptor. Annual Review of Immunology 15: 453-479.

Roederer, J. (2005). Information and its Role in Nature. Springer Verlag, Berlin. 
Ronald, E.M.A., M. Sipper and M.S. Capcarrère (1999). Design, observation, surprise! A test for emergence. Artificial Life 5: 225-239.

Rosenthal, S. (1994). Charles Peirce's Pragmatic Pluralism. State University of New York Press, New York.

Salthe, S.N. (1985). Evolving Hierarchical Systems: Their Structure and Representation. Columbia University Press, New York.

Salthe, S.N. (1993). Development and Evolution: Complexity and Change in Biology. MIT Press, Cambridge, MA.

Savan, D. (1986). Response to T.L. Short. Transactions of the Charles S. Peirce Society: A Quarterly Journal in American Philosophy, Summer XXII(2): 125-143.

Sebeok, T. (1989). The Sign and its Masters. University Press of America, New York.

Seyfarth, R., D.L. Cheney and P. Marler (1980). Monkey responses to three different alarm calls: Evidence of predator classification and semantic communication. Science (210): 801-803.

Stephan, A. (1998). Varieties of emergence in artificial and natural systems. Zeitschrift für Naturforschung 53c: 639-656.

Stephan, A. (1999). Emergenz: Von der Unvorhersagbarkeit zur Selbstorganisation. Dresden and München: Dresden University Press. 